Article

\title{
Improved Virtual Inertia of PMSG-Based Wind Turbines Based on Multi-Objective Model-Predictive Control
}

\author{
Shiyao Qin ${ }^{1,2}$, Yuyang Chang ${ }^{3}$, Zhen $\mathrm{Xie}^{3, *}$ and Shaolin $\mathrm{Li}^{2}$ \\ 1 School of Electrical Engineering, Southeast University, Nanjing 210096, China; qinshy@epri.sgcc.com.cn \\ 2 China Electric Power Research Institute, Beijing 100192, China; lishaolin@epri.sgcc.com.cn \\ 3 School of Electrical Engineering and Automation, Hefei University of Technology, Hefei 230009, China; \\ changyuyang1995@163.com \\ * Correspondence: ppsd2003xie@sina.com
}

Citation: Qin, S.; Chang, Y.; Xie, Z.; $\mathrm{Li}$, S. Improved Virtual Inertia of PMSG-Based Wind Turbines Based on Multi-Objective Model-Predictive Control. Energies 2021, 14, 3612. https://doi.org/10.3390/ en14123612

Academic Editors: Ambrish Chandra and Hua Geng

Received: 20 April 2021

Accepted: 10 June 2021

Published: 17 June 2021

Publisher's Note: MDPI stays neutral with regard to jurisdictional claims in published maps and institutional affiliations.

Copyright: (c) 2021 by the authors. Licensee MDPI, Basel, Switzerland. This article is an open access article distributed under the terms and conditions of the Creative Commons Attribution (CC BY) license (https:// creativecommons.org/licenses/by/ $4.0 /)$.

\begin{abstract}
In the case of a high penetration rate of wind energy conversion systems, the conventional virtual inertia control of permanent magnet synchronous generators (PMSG) has an insufficient support capability for system frequency, leading to an unstable system frequency and a slower response. Considering the finite control set model predictive control has multi-objective regulation capabilities and efficient tracking capabilities, and an improved multi-objective model-predictive control is proposed in this paper for PMSG-based wind turbines with virtual inertia based on its mathematical model. With the prediction model, the optimal control of the current and the frequency of the PMSG-based wind turbines can be obtained. Since the shaft torque changes rapidly under high virtual inertia, shaft oscillation may occur under this scenario. To address this problem, the electromagnetic torque is set as an additional optimization objective, which effectively suppresses the oscillation. Furthermore, based on accurate short-term wind speed forecasting, a dynamic weight coefficient strategy is proposed, which can reasonably distribute the weight coefficients according to the working conditions. Finally, simulations are carried out on a 2 MW PMSG-based wind turbine platform, and the effectiveness of the proposed control strategies is verified.
\end{abstract}

Keywords: permanent magnet synchronous generators; virtual inertia; multi-objective model predictive control; dynamic weight coefficient

\section{Introduction}

In recent decades, the wind power industry has developed rapidly throughout the world, and the capacity of newly installed systems has been continuously reported. The expanding capacity of wind energy conversion systems (WECS) and the increase in wind power plants have increasingly caused problems, especially in the case of long-distance power transmission [1,2]. In power systems with high penetration of wind power, it is important to maintain frequency stability. Therefore, many countries and regions in the world have standardized the inertia and frequency regulation of wind power through the grid codes, which motivate the wind power to actively participate in the system frequency response based on either the market incentives or the mandatory regulations. The grid codes require that wind turbines should have a certain inertia response time, which represents the time from the start of the response until the inertial compensation power reaches the set value. In the development of wind power technology, direct-driven permanent magnet synchronous generator (D-PMSG) has shown great potential. It is not equipped with gearboxes, which further reduces cost and failure rate. When large-capacity and high-scale PMSGs are connected to the power grid, it is still expected to reduce the losses and improve the quality of wind power $[3,4]$.

However, the increasing penetration of wind power plants may jeopardize the power system's stability due to their stochastic characteristics and the lack of inertia response, as the rotor speed is decoupled with the grid frequency by electronic power devices $[5,6]$. 
Hence, the integration of wind turbines (WTs) has posed more challenges for the operation of power systems. Existing studies have analyzed the inertia regulation of WECS, and the control strategies can be divided into two categories. One is virtual synchronization control (VSC) on the grid side control (GSC), the other is to provide virtual inertial power by the power reference of the machine-side control (MSC) in the WECS [7,8]. The VSC controls the external characteristics of the converter by simulating the characteristics of the synchronous generator and achieves the effect of frequency modulation by power droop. Virtual Inertial Power Control refers to the virtual inertial power generated by adding frequency deviation on the power instruction on the basis of the original current source control. The control principle of the two control methods is completely different from that of the synchronous mode. The characteristics of the synchronous generator are used to improve the inertia regulation capability. The authors of Refs. $[9,10]$ mainly studied the control mode of virtual synchronization on the grid side. In Ref. [9], the authors mainly used the DC voltage to obtain the output frequency and provide the virtual inertia. In Ref. [10], the effects of various parameters were analyzed in the virtual inertia control structure. The virtual synchronization control is suitable for weak power grids but has few practical applications. A PMSG-based small-signal model for low-voltage ride-through (LVRT) wind turbines suitable for stability and artificial intelligence research is proposed in Ref. [11]. Accordingly, the DC link voltage is controlled by the generator-side converter, and the maximum power point tracking is performed by the grid-side converter.

This paper mainly studies the inertia control strategy of MSC. In Refs. [12,13], the authors mainly realized the inertia optimization control by changing the maximum power point tracking (MPPT) curve and analyzed the additional inertia of the system. The authors of Ref. [14] mainly solved the problems of rotor kinetic energy compensation and frequency secondary drop in the process of power grid frequency regulation. The small-signal stability considering the phase-locked loop with virtual inertia was analyzed in Ref. [15]. The control of the system frequency in the case of mechanical oscillations was proposed in Ref. [16], and the influence of the virtual inertia on this control was specifically analyzed by a small signal model in Ref. [17]. In Ref. [18], the author achieved active power control by model predictive control (MPC), and the frequency regulation method based on MPC was introduced in Ref. [19]. Although the strategies provided by the above papers can optimize the virtual inertia, the combined optimization of mechanical oscillation, additional virtual inertial power, and wind speed is rarely involved.

In this paper, a current-frequency multi-objective optimization control is proposed for PMSG-based WTs based on finite set model predictive control (FCS-MPC). Compared with the existing works, the following three improvements can be achieved:

(a) Combining the characteristics of the exponential function, the idea of the dynamic weight coefficient is introduced into the cost function. Because of the high degree of accuracy in short-term wind speed forecasting, the dynamic weight coefficient strategy [20] based on wind speed forecasting is proposed, which dynamically adjusts the weight coefficient of the PMSG-based WTs at different wind speeds and different working conditions, changes the output quality requirements for different quantities, and better coordinates the quality requirements for different output quantities under different conditions.

(b) To provide sufficient virtual inertia with a fast response speed, a current-frequency multi-objective optimization control is proposed for PMSG-based WTs based on FCS-MPC. According to the frequency response model, the frequency difference is predicted. The improved control of the system frequency is realized compared to the conventional method. The support capability to the system frequency can be adjusted by changing the weight coefficient of the objectives.

(c) Since the electromagnetic torque is proportional to the shaft torque, the shaft torque can be suppressed by suppressing the electromagnetic torque in the frequency response. The main control method in this paper is to include torque control in the optimization control objective. After increasing the virtual inertia, the shaft oscillation 
caused by the excessive shaft torque is suppressed by the current-frequency-torque multi-objective MPC and reduces the instantaneous virtual power shock in the virtual inertia compensation link by adjusting the weight coefficient. In addition, the loss on the shaft can be reduced, which is conducive to the stability of the WECS.

The overall structure of this paper is as follows. Section 2 lists the mathematical and predictive models of PMSG. Section 3 analyzes the characteristics of the conventional additional virtual inertia structure and notes its problems. Furthermore, the optimization control strategy and dynamic weight coefficient strategy are introduced in Section 4.1. The 2 MW PMSG-based WT simulation platform is built for verification in Section 5. Conclusions are drawn in Section 6.

\section{Mathematical Model Of PMSG}

\subsection{Model Of PMSG}

There are many ways to orient the PMSG mathematical model in the controller. In this paper, the PMSG field-oriented control strategy is adopted since the control strategy based on the rotor flux linkage is simple and practical. Through the detection of the rotor position angle and rotation speed of PMSG, the control strategy can be realized using the Park transformation [21,22].

In the $d q$-axis synchronous rotating coordinate system, the mathematical model of PMSG can be expressed as follows:

$$
\begin{gathered}
{\left[\begin{array}{l}
u_{d} \\
u_{q}
\end{array}\right]=\left[\begin{array}{cc}
R_{s}+p L_{d} & -\omega_{g} L_{q} \\
\omega_{g} L_{d} & R_{s}+p L_{q}
\end{array}\right]\left[\begin{array}{l}
i_{d} \\
i_{q}
\end{array}\right]+\left[\begin{array}{c}
0 \\
\psi_{f}
\end{array}\right] \omega_{g}} \\
{\left[\begin{array}{l}
\psi_{d} \\
\psi_{q}
\end{array}\right]=\left[\begin{array}{cc}
L_{d} & 0 \\
0 & L_{q}
\end{array}\right]\left[\begin{array}{l}
i_{d} \\
i_{q}
\end{array}\right]+\left[\begin{array}{c}
\psi_{f} \\
0
\end{array}\right]}
\end{gathered}
$$

The relationship between the current at instant $k+1$ and the current at instant $k$ can be obtained through the discretization of Equation (1). The details of the adopted discretization technique can be found in References [23,24], as shown in Equation (3), where $k$ represents the value of the variable at the present moment and $k+1$ represents the variable at the next moment. It can be concluded from Equation (3) that the predicted $d q$-axis current at instant $k+1$ is related to the stator voltage and the $d q$-axis current at instant $k$.

$$
\left[\begin{array}{c}
i_{d}(k+1) \\
i_{q}(k+1)
\end{array}\right]=\left[\begin{array}{cc}
\left(1-T_{S} R_{s} / L_{d}\right) & T_{S} W_{e} L_{q} / L_{d} \\
-T_{S} W_{e} L_{d} / L_{q} & \left(1-T_{S} R_{s} / L_{q}\right)
\end{array}\right]\left[\begin{array}{c}
i_{d}(k) \\
i_{q}(k)
\end{array}\right]+\left[\begin{array}{cc}
T_{S} / L_{d} & 0 \\
0 & T_{S} / L_{q}
\end{array}\right]\left[\begin{array}{c}
u_{d}(k) \\
u_{q}(k)
\end{array}\right]+\left[\begin{array}{c}
0 \\
T_{s} W_{e} / L_{q}
\end{array}\right] \psi_{f}
$$

The active power model and the electromagnetic torque model of the system can be expressed as follows:

$$
\begin{gathered}
P_{e}=\frac{3}{2}\left(\psi_{d} i_{q}-\psi_{q} i_{d}\right) \omega_{e}=\frac{3}{2} p_{n}\left(\psi_{d} i_{q}-\psi_{q} i_{d}\right) \Omega \\
T_{e}=\frac{P_{e}}{\Omega}=\frac{3}{2} p_{n}\left(\psi_{d} i_{q}-\psi_{q} i_{d}\right)
\end{gathered}
$$

Combined with the flux linkage model, the simplified mathematical model of the active power and electromagnetic torque can be deduced as follows:

$$
\begin{gathered}
P_{e}=\frac{3}{2} p_{n}\left[\psi_{f} i_{q}+\left(L_{d}-L_{q}\right) i_{d} i_{q}\right] \Omega \\
T_{e}=\frac{3}{2} p_{n}\left[\psi_{f} i_{q}+\left(L_{d}-L_{q}\right) i_{d} i_{q}\right]
\end{gathered}
$$


In Equation (8), the electromagnetic torque-predictive model can be obtained after discretization.

$$
T_{e}(k)=\frac{3}{2} p_{n}\left[\psi_{f} i_{q}(k)+\left(L_{d}-L_{q}\right) i_{d}(k) i_{q}(k)\right]
$$

In addition, since positive values of torque and power should mean generator operation, current/torque/power signs are changed properly during control system design.

\subsection{Model of Drive Chain}

The related equation above can be used to realize the MPC system, and the current and electromagnetic torque can be calculated to achieve the optimization in the system. The wind turbine drive system of a permanent magnet synchronous generator can usually be equivalent to a two-mass module $[25,26]$.

$$
\begin{gathered}
\frac{d \theta_{s}}{d t}=\omega_{g}-\omega_{r} \\
\frac{d \omega_{r}}{d t}=\frac{K_{s}}{J_{r}} \theta_{s}+\frac{B_{s}}{J_{r}} \omega_{g}-\frac{B_{s}}{J_{r}} \omega_{r}-\frac{T_{r}}{J_{r}} \\
\frac{d \omega_{g}}{d t}=-\frac{K_{s}}{J_{g}} \theta_{s}-\frac{B_{s}}{J_{g}} \omega_{g}+\frac{B_{s}}{J_{g}} \omega_{r}+\frac{T_{e}}{J_{g}}
\end{gathered}
$$

Equations (9)-(11) are the mathematical models of the two-mass system. The two-mass model can be used to analyze the effect of virtual inertia on shaft oscillation.

\section{Conventional Virtual Inertia Control for PMSG-Based WTs}

\subsection{Control Structure}

The conventional additional virtual inertia structure of PMSG-based WTs is shown in Figure 1. The grid side uses vector control and a PI controller to control the inductor current and the DC-link voltage. The virtual inertia power is added to the power reference to achieve inertia compensation. According to the GSC in Figure 1, the frequency is detected through the phase-locked loop, and the frequency deviation and frequency differential calculations are performed. Finally, the virtual inertial power instruction is obtained. When the grid frequency fluctuates, the frequency response of the grid is affected by the virtual inertial power. The advantages and disadvantages of conventional vector control are obvious. The advantage of the PI controller is that it can adjust the tracking capability of control variables and adapt to various system models. The disadvantage is that it cannot regulate multiple related variables or improve the performance of the system to achieve multiple control objectives.

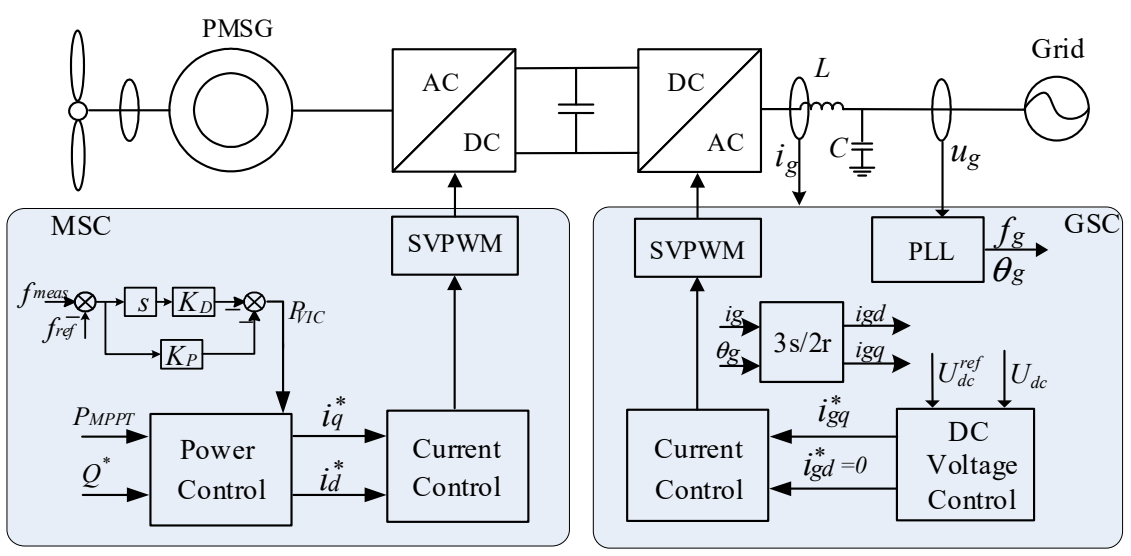

Figure 1. Conventional virtual inertia control structure. 


\subsection{PD Virtual Inertia Control and Problems}

The proportion-differential $(P D)$ virtual inertia control of PMSG-based WTs simulates the characteristics of synchronous generators. As shown in Figure 2, when the system frequency fluctuates, the additional power related to the system frequency deviation and differential takes effect, which can cause the WTs to change their output power. This control strategy realizes the simulation of the primary regulation characteristic and the inertial response characteristic of a traditional synchronous generator. The mathematical model of the virtual inertial power can be expressed as follows:

$$
P_{V I C}=-K_{d} \frac{d f_{d e v}}{d t}-K_{p} f_{d e v}
$$

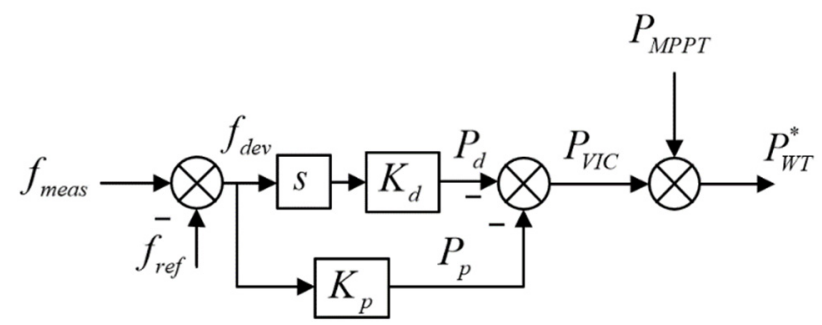

Figure 2. $P D$ virtual inertia control structure.

Through the discretization and simplification, the frequency-prediction model of the PMSG-based WTs with additional inertial power adjustment can be obtained. Since the WT is decoupled from the power of the grid without additional inertia, the predicted frequency deviation is related to the virtual inertia power and frequency deviation emitted by the WT at instant $k$.

$$
f_{\text {dev }}(k+1)=\left(1-\frac{K_{p} T_{s}}{K_{d}}\right) f_{\text {dev }}(k)-\frac{T_{s}}{K_{d}} P_{V I C}(k)
$$

To study the frequency support capability of high-penetration wind power in the WECS, it is necessary to establish a frequency response model of the conventional thermal power generation system. In the analysis of the system frequency adjustment, the internal model of the thermal power unit can be ignored, and the structure is simplified. According to the relationship between the frequency variation and output power, the frequency response model can be established [27], as shown in Equation (14). With a larger $M$, the system frequency changes more slowly under the same power deviation disturbance. Moreover, with a larger $D$, the steady-state output power of the system is higher, and the frequency dynamics are improved.

$$
f_{d e v}=P_{d e v}\left(\frac{1}{M s+D}\right)
$$

For the convenience of analysis, Equation (14) can be expressed as Equation (15).

$$
\frac{d f_{d e v}}{d t}=\frac{P_{d e v}-D f_{d e v}}{M}
$$

After the virtual inertia control is introduced in the PMSG-based WTs introduced in Equation (12), the frequency response equation of the system is changed from Equation (15) to Equation (16).

$$
\frac{d f_{d e v}}{d t}=\frac{P_{d e v}+P_{V I C}-D f_{d e v}}{M}
$$

After the combination, Equation (17) can be obtained.

$$
\frac{d f_{d e v}}{d t}=\frac{P_{d e v}-\left(D+K_{p}\right) f_{d e v}}{M+K_{d}}
$$


Comparing Equations (15) and (17) shows that the system frequency deviation can be further reduced when a disturbance occurs with the virtual inertia regulation capability of the WT. The PD virtual inertia control improves the system frequency stability in terms of the inertia and damping. Therefore, the virtual inertia control of PMSG-based WTs can simulate the rotor dynamic equation of the synchronous generator, and the PMSG-based WTs can respond to the grid frequency change and provide the virtual inertia for the grid.

Conventional virtual inertia control has some problems in the case of high wind power penetration [28]. In general, the inertia coefficient of the synchronous generator is larger than the inertia coefficient provided by the PMSG-based WTs. On the one hand, as the proportion of wind power increases, the total inertia of the system drops significantly. This is because the proportion of synchronous units with a stronger frequency regulation capability is reduced, and the current setting of $K_{d}$ parameters cannot meet the original inertia level of the power system. On the other hand, as the $K_{d}$ coefficient increases with the same wind power proportion, the total inertia of the system rises. The analysis above not only shows that increasing the virtual inertia coefficient of the system is beneficial for adjusting the frequency under the condition of high wind power penetration, but that it is also the reason for optimizing the inertia of the power system in the conventional virtual inertia control strategy.

However, the effect of excessive virtual inertia cannot be ignored for the PMSG shaft torque. Although the shaft torque of the PMSG is very close to the maximum torque of the generator, the change rate of the shaft torque is much higher than the rate of change of the generator torque, which may cause fatigue in the WTs. If the virtual inertia is too large, the torsion angle and the rotor speed of the shaft deviating from the stable state will cause free oscillation of the shaft system. The repeated tightening and relaxation of the shaft torque will damage the shaft and affect the stability of the WECS. Since the main factor affecting shaft oscillation is the electromagnetic torque, and since the electromagnetic torque is easier to be obtained than the shaft torque, the control strategy of this paper uses MPC to limit the electromagnetic torque of the PMSG.

\section{Optimization Control Strategy Design and Analysis}

\subsection{FCS-MPC Control and Optimization}

In the application of power electronic control, FCS-MPC needs to traverse all preselected switch states within a sampling period and then compare the output of the cost function under different vectors according to the pre-designed cost function related to system performance to select the best switch vector $[29,30]$.

To reduce the calculation process and the switching frequency, this paper adopts a strategy of switching vector optimization selection. The various switching states in the traditional MPC switching vector can be switched at will. The optimized switching vector is shown in Figure 3 [31]. When the switching vector of the previous cycle is a zero vector, it can switch to any nonzero vector. When the switching vector of the previous cycle is nonzero, it can only switch to its adjacent vector or maintain its own vector. In this way, by limiting the number of times the switching tube operates in a single cycle, the purpose of reducing the switching frequency is achieved.

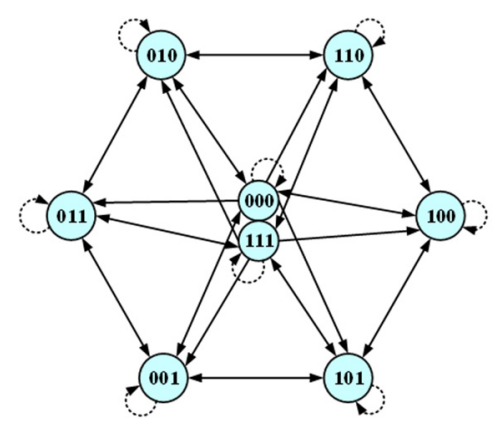

Figure 3. Switching vector optimization selection. 


\subsection{The Structure of Multi-Objective MPC}

According to the stator current prediction equation, the frequency prediction equation, and the electromagnetic torque prediction equation of the PMSG derived in Sections 2 and 3, the improved PMSG multi-objective MPC structure is established. In Figure 4, the GSC maintains the conventional vector control [32], the grid voltage vector is oriented on the $q$ axis, and the $q$ axis controls the output of the active power. This includes the grid-side inductor current loop and the DC voltage loop to maintain the stability of the grid side current and the DC-link voltage. The MSC adopts the multi-objective MPC by predicting the current and calculating the optimized objectives, and the final selected voltage vector is used for MPC through a rolling optimization combined with the FCS-MPC algorithm. The cost function is composed of three parts: current, frequency, and torque.

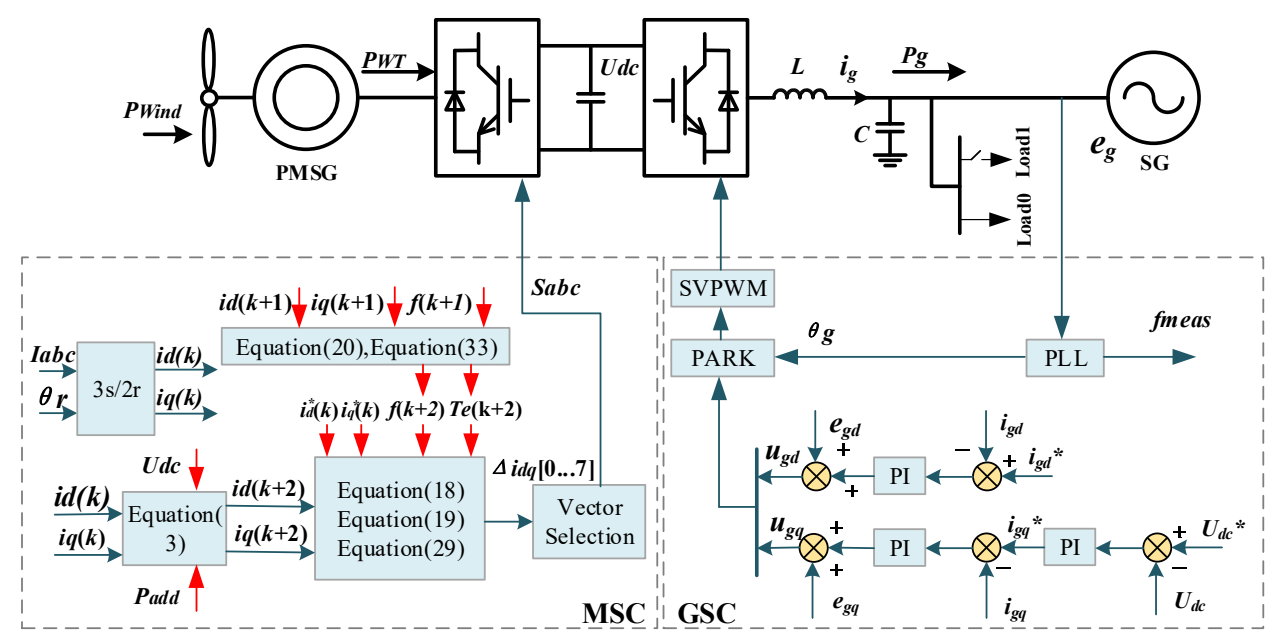

Figure 4. Diagram of the multi-objective MPC structure.

In the conventional virtual inertia control of PMSG-based WTs, the frequency is obtained by the phase-locked loop detection, and the compensation value is added to the current reference. With the selection strategy of the optimal vector in the FCS-MPC, the frequency support capability is higher than the conventional virtual inertia control. By adding the electromagnetic torque prediction model to the cost function, the adverse effects of excessive virtual inertia are optimized. By then standardizing the weight coefficient and the active power of the system, the weight coefficients are allocated according to the wind power proportion. With accurate wind speed forecasting, the value of the weight coefficient is changed dynamically. The stability of the WECS is improved. According to different working conditions and different control objectives, the control of this paper can be divided into current MPC, current-frequency double-objective MPC, and current-frequency-torque multi-objective MPC [33,34].

\subsection{The Modes of Multi-Objective MPC}

In the actual digital experiment process, FCS-MPC is executed in the DSP (Digital Signal Processor). Due to the large time consumption of the algorithm itself, the switching action at two times is inconsistent with the sampling time. The inconsistency of this segment is due to the delay, and the switching vector at instant $k$ cannot be executed immediately, which will have an impact on FCS-MPC. According to the current-sampling signal, the $i(k+1)$ of the system is calculated. Based on $i(k+1)$, the current value $i(k+2)$ of the system can be calculated. The optimal switching vector $S(k+1)$ is selected in $i(k+2)$ to be executed immediately at instant $k+1$, and the control error will be reduced in this way. These calculation processes are all completed in one sampling period, and this paper uses this two-step MPC for the control modes as follows. 


\subsubsection{Current-Frequency Double-Objective MPC}

Based on the prediction model of the stator current, the cost function can be expressed as in Equation (18).

$$
J(k)=\left|i_{d}^{*}(k+2)-i_{d}(k+2)\right|^{2}+\left|i_{q}^{*}(k+2)-i_{q}(k+2)\right|^{2}
$$

In the previous sections, the current model and the frequency model are introduced in detail. The cost function can be expressed as given in Equation (19). The current-frequency double-objective control using current prediction and frequency prediction can optimize the virtual inertial power provided by the conventional $P D$ virtual inertia control and improve the frequency response. The purpose of changing the cost function is to select the smallest value of the cost function with the frequency deviation. The smallest value determines the switching vector at instant $k+1$, and the weight coefficient determines the strength of the system in tracking between frequency and current.

$$
J(k)=\alpha\left(\left|\left(i_{d}^{*}(k+2)-\left.i_{d}(k+2)\right|^{2}+\left|i_{q}^{*}(k+2)-i_{q}(k+2)\right|^{2}\right)+\beta\right| f_{\text {dev }}^{*}(k+2)-\left.f_{\text {dev }}(k+2)\right|^{2}\right.
$$

After establishing the cost function, it is necessary to obtain the prediction value required by the cost function. In Equation (20), the frequency deviation prediction value at instant $k+1$ is related to the frequency deviation and the power deviation at instant $k$. The current prediction can be used to calculate different predicted current values under different voltage vectors at instant $k+1$. By subtracting the steady-state component of the current from the predicted current at instant $k+1$, the current deviation component at instant $k+1$ can be obtained. The power deviation component can be calculated by the current deviation component.

$$
f_{d e v}(k+2)=\left[1-\frac{\left(K_{p}+D\right) T_{s}}{K_{d}+M}\right] f_{d e v}(k+1)+\frac{T_{s}}{K_{d}+M} P_{d e v}(k+1)
$$

It should be noted that during the sampling period, since the sampling frequency is much greater than the grid frequency change, the grid frequency change at time $k$ can be considered to vary linearly. As shown in Equation (21), the frequencies at instants $k$ and $k-1$ are calculated equivalently to obtain the approximate frequency deviation at instant $k+1$. After obtaining the control variables of instant $k+1$, the frequency deviation at instant $k+2$ can be calculated. In addition, considering that the proportional coefficient $K_{p}$ has a smaller impact on the dynamic response of the system compared to the differential coefficient, the proportional coefficient $K_{p}$ is chosen to be ignored, and this paper mainly analyzes the differential part of the $P D$ control. The frequency prediction in Equation (20) is transformed into Equation (22).

$$
\begin{gathered}
f_{\text {dev }}(k+1) \approx f_{\text {dev }}(k)+\left(f_{\text {dev }}(k)-f_{\text {dev }}(k-1)\right)=2 f_{\text {dev }}(k)-f_{\text {dev }}(k-1) \\
f_{\text {dev }}(k+2)=\left(1-D T_{s} /\left(K_{d}+M\right)\right) f_{d e v}(k+1)+T_{s} P_{d e v}(k+1) /\left(K_{d}+M\right)
\end{gathered}
$$

Since only the differential coefficient is considered, the calculation of compensation current is approximated by the compensated virtual inertia power, as shown in the following equation:

$$
i_{\text {add }}(k)=\frac{P_{V I C}}{\frac{3}{2} p_{n} \psi_{f} \Omega(k)}=\frac{-K_{d}}{\frac{3}{2} p_{n} \psi_{f} \Omega(k)} \frac{f_{d e v}(k)-f_{d e v}(k-1)}{T_{s}}
$$

By adding the compensation current to the $q$-axis current in formula (6), we can obtain the active power in PMSG at the frequency response: 


$$
\left\{\begin{array}{c}
P_{e}(k+1)=\frac{3}{2} P_{n}\left\{\psi_{f}\left(i_{q}(k+1)+i_{\text {add }}(k+1)\right)+\left(L_{d}-L_{q}\right) i_{d}(k+1)\left(i_{q}(k+1)+i_{\text {add }}(k+1)\right)\right\} \Omega(k+1) \\
P_{e}(k+1)=\frac{3}{2} P_{n}\left\{\psi_{f}\left[i_{q}(k+1)-\frac{K_{d}}{\frac{3}{2} p_{n} \psi_{f} \Omega(k+1)} \frac{f_{\text {dev }}(k+1)-f_{\text {dev }}(k)}{T_{s}}\right]+A\right\} \Omega(k+1) \\
A=\left(L_{d}-L_{q}\right) i_{d}(k+1)\left[i_{q}(k+1)-\frac{K_{d}}{\frac{3}{2} p_{n} \psi_{f} \Omega(k+1)} \frac{f_{\text {dev }}(k+1)-f_{\text {dev }}(k)}{T_{s}}\right]
\end{array}\right.
$$

The steady-state component can be expressed as follows:

$$
P_{e s}(k+1)=1.5 p_{n}\left[\psi_{f} i_{\text {gref }}(k)+\left(L_{d}-L_{q}\right) i_{\text {dref }}(k) i_{\text {gref }}(k)\right] \Omega(k+1)
$$

Since the current prediction can make the current stably track the reference value, this paper assumes that the current weight coefficient is sufficiently large, so the current at instant $k+1$ is close to the steady-state current reference at instant $k$.

$$
P_{e s}(k+1)=1.5 p_{n}\left[\psi_{f} i_{q}(k+1)+\left(L_{d}-L_{q}\right) i_{d}(k+1) i_{q}(k+1)\right] \Omega(k+1)
$$

In the conventional control, the value of the active power is controlled by the q-axis current, so Equation (25) can be expressed as in Equation (27).

$$
P_{e s}(k+1)=1.5 p_{n} \psi_{f} i_{\text {qref }}(k) \Omega(k+1)
$$

After subtracting the steady-state component, the final power deviation component of PMSG is expressed by Equation (28) through simplification.

To compensate for the lack of virtual inertial power in the original system, the power deviation component model in Equation (28) is deduced, and the frequency deviation component is changed to Equation (29). The compensation coefficients $M$ and $D$ are introduced in Equation (29) to simulate the inertia and damping of the grid in the prediction model.

$$
\begin{gathered}
P_{d e v}(k+1)=P_{e}(k+1)-P_{e s}(k+1)=-K_{d} \frac{f_{d e v}(k+1)-f_{d e v}(k)}{T_{s}} \\
P_{d e v}(k+1)=\left[P_{e}(k+1)-P_{e s}(k+1)\right]-M \frac{f_{d e v}(k+1)-f_{d e v}(k)}{T_{s}}-D f_{d e v}
\end{gathered}
$$

The optimization cost function considers both the current and frequency objectives. However, without limiting the torque, the electromagnetic torque and torque change rate during the frequency response will change abruptly with the increase in the virtual inertia. From the analysis in Section 3, the excessive shaft torque is very harmful and affects the stability of the system.

\subsubsection{Current-Frequency-Torque Multi-Objective MPC}

To suppress the fluctuation of the shaft torque during frequency regulation, this paper proposes current-frequency-torque multi-objective control. This control strategy can limit the drive shaft torque fluctuation caused by the additional inertia and maintain the stability of the system. The cost function is converted into Equation (30). The purpose is to suppress the fluctuation of the system torque caused by the disturbance while suppressing the frequency fluctuation and to control the virtual inertia power within a reasonable range. The frequency prediction value can be obtained by referring to the strategy of the current-frequency prediction. Since the d-q axis currents have been previously extracted, the electromagnetic torque prediction value can be calculated by Equation (8).

$$
\begin{gathered}
J(k)=\alpha\left(\left|\left(i_{d}^{*}(k+2)-\left.i_{d}(k+2)\right|^{2}+\left|i_{q}^{*}(k+2)-i_{q}(k+2)\right|^{2}\right)+\beta\right| f_{d e v}^{*}(k+2)-\left.f_{\text {dev }}(k+2)\right|^{2}\right. \\
+\gamma\left|T_{e}^{*}(k+2)-T_{e}(k+2)\right|^{2}
\end{gathered}
$$


The reference value of the electromagnetic torque can be obtained through analogy with the steady state-value of the power, which can be expressed as Equation (31).

$$
T_{e}^{*}(k+2) \approx T_{e}^{*}(k)=1.5 p_{n}\left[\psi_{f} i_{\text {qref }}(k)+\left(L_{d}-L_{q}\right) i_{\text {dref }}(k) i_{\text {qref }}(k)\right]
$$

The predicted value of the electromagnetic torque can be expressed as Equation (32).

$$
T_{e}(k+2)=1.5 p_{n}\left[\psi_{f} i_{q}(k+2)+\left(L_{d}-L_{q}\right) i_{d}(k+2) i_{q}(k+2)\right]
$$

In the conventional control, the magnitude of the active current is controlled by the $q$ axis current, and the electromagnetic torque reference and predicted value can be simplified to Equations (33) and (34).

$$
\begin{gathered}
T_{e}^{*}(k+2)=1.5 p_{n} \psi_{f} i_{\text {qref }}(k) \\
T_{e}(k+2)=1.5 p_{n} \psi_{f} i_{q}(k+2)
\end{gathered}
$$

This control solves the problem of shaft oscillation when the weight coefficient of the frequency deviation is set to be large. The additional electromagnetic torque control can effectively suppress the negative influence caused by the sudden change in the torque of the shaft. However, according to the different conditions of the torque under different wind speed conditions, the weight coefficient needs to be adaptively changed.

\subsection{The Weight Coefficient Selection}

\subsubsection{Standardization Weight Coefficient Calculation}

Because of the different control capabilities of multi-objective control with its weight coefficient, the stator current, frequency deviation, and electromagnetic torque are standardized according to their respective rated value and rated power. The control capability can be reasonably adjusted in this standard. The active power of the WECS is taken as the base value, and the weight coefficient is adjusted according to the control effect in the actual control. The weight coefficient can be expressed as follows:

$$
\alpha=\lambda_{I} \beta=\lambda_{f}\left(I_{n} / f_{d e v, n}\right)^{2} \gamma=\lambda_{T}\left(I_{n} / T_{e, n}\right)^{2}
$$

The rated value of the frequency deviation and the rated value of the torque need to be selected in combination with the maximum steady frequency, which the system allows. Generally, the weight coefficients calculated in this way may have problems in actual use and need to be adjusted in the actual system. If the optimization effect on each part needs to be improved, the weight coefficient should be increased. For example, if the current tracking effect needs to be improved, the current weight coefficient should be increased.

\subsubsection{Weight Coefficient Adaptive Strategy Based on Wind Speed Forecasting}

Wind speed forecasting plays an important role in wind power generation. Wind speed forecasting technology is very mature. The short-term forecasting of wind speed can be used to predict the short-term power of PMSG-based WTs. It has important practical value for improving the capability of the PMSG-based WTs, improving the grid connection level, and reducing the cost of wind power in virtual inertia control. When the forecast duration of the short-term forecast is $1 \mathrm{~s}$, the mean absolute percentage error (MAPE) reflecting the prediction accuracy is less than $5 \%$, which is sufficient for dynamic adjustment [35-37]. The power of the inertia that the PMSG-based WTs can provide under different working conditions is limited, so the WTs cannot provide excessive active power during the virtual inertia adjustment process. According to the cost function above, a strategy for transforming the weight coefficient in different wind speeds is proposed [38,39].

To adjust the weight coefficient dynamically, it is necessary to select the most suitable values of $\lambda_{I}, \lambda_{f}$, and $\lambda_{T}$ that satisfy the system active power by adjusting the weight coefficient under the standard conditions. In the case of obtaining the forecasted wind 
speed, the corresponding predicted active power is calculated by MPPT [40]. When the wind speed is changed, the predicted active power is also changed. To deal with problems caused by different wind speeds, the control strategy can be obtained by the dynamic weight coefficient strategy. Furthermore, this method can reduce the delay and error of direct power detection.

In order to achieve variable weight coefficients, exponential function Equation (36) can be introduced. Based on the exponential function Equation (36), the characteristics of the dynamic weight coefficient are analyzed. It is shown from Figure 5 that if $P_{f} / P_{s}$ is less than 1, the forecasted power is less than the rated power of the WT in the exponential function equation. The larger the selected $\mathrm{N}$ is, the smaller the function value of the final output is. When $P_{f} / P_{S}$ is greater than 1 , the forecasted power is greater than the rated power of the WT. The larger the selected N is, the larger the function value of the final output is. Through the above analysis, it is concluded that different exponential functions should be selected for different actual situations, and the dynamic weight coefficient control strategy can be realized. When the wind speed is high, increasing the weight coefficient can make the exponential function output more sensitive.

$$
\text { Function }=\left(P_{f} / P_{s}\right)^{N}
$$

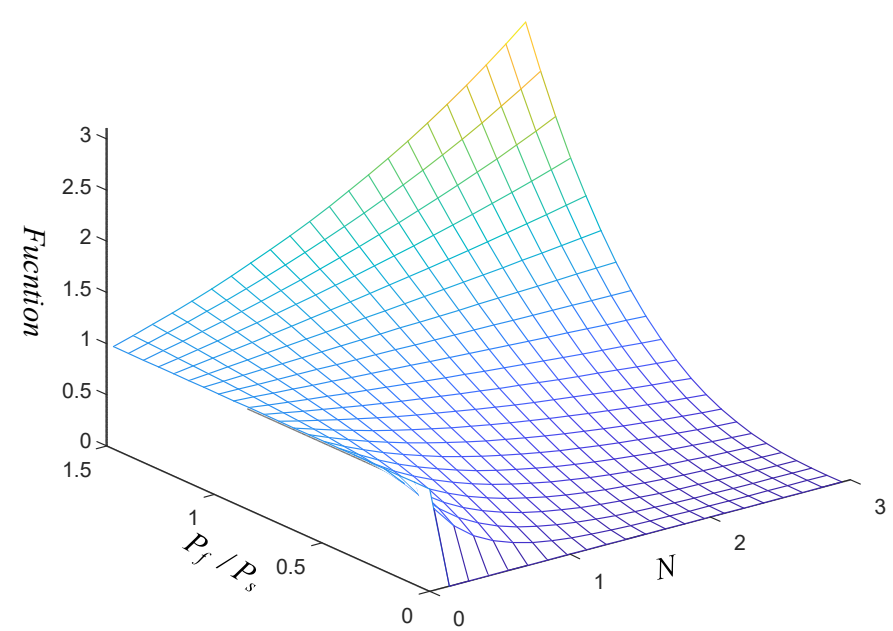

Figure 5. The relationship between $P_{f} / P_{\mathrm{s}}, N$, and the function values.

To ensure the stability of the output current, it is necessary to limit the weight of the current, as shown in Equation (37). Assuming that the PMSG-based WTs operate in the MPPT area and the power change does not reach the highest power, Equation (38) can be derived by selecting the exponential function. To prevent the influence of excessive coefficient change on the control stability, the limit is set. This can be obtained from Equation (38). Under different wind speeds, the weight coefficient changes to ensure that the wind turbine can provide sufficient power for the frequency response. As shown in Equation (39), in the case of a low wind speed, the influence on the shaft torque variation is reduced. At this time, the torque weight coefficient can be reduced to increase the frequency control capability. The effect of the exponential function is reversed at high wind speeds. Selecting 5 as the value of $N$ increases the sensitivity of the wind turbine and limits the shaft torque when the power is exceeded so that the torque weight coefficient at a high wind speed is rapidly increased to limit the output shaft torque. It should be emphasized that in the process of control adjustment, if any control objective reaches the limit value, the weight coefficient of each optimization objective no longer acts.

$$
\alpha(k)=\left\{\begin{array}{c}
\alpha \\
\alpha_{\text {min }} \quad \alpha \text { below the } \alpha_{\text {min }}
\end{array}\right.
$$




$$
\begin{array}{r}
\beta(k)= \begin{cases}\beta_{\max } & P_{f} \text { over the maximum } \\
& \beta_{n}\left(P_{f} / P_{s}\right)^{2} \\
\beta_{\min } & P_{f} \text { below the minimum }\end{cases} \\
\gamma(k)= \begin{cases}\gamma_{\max } & P_{f} \text { over the maximum } \\
& \gamma_{n}\left(P_{f} / P_{s}\right)^{5} \\
\gamma_{\min } & P_{f} \text { below the minimum }\end{cases}
\end{array}
$$

There is a coupling relationship between each weighting coefficient in the multiobjective MPC, where the weight coefficients of the torque and current in the cost function are also affected when the frequency weight coefficient is changed. The weight coefficient impact on performance is qualitatively analyzed. Assuming that the sum of the percent of the three objectives is 1, Equation (40) can be obtained. The wind speed forecasting is added to Equation (40), and then Equation (41) can be deduced. When the wind speed and the active power are reduced, the frequency coefficient and the torque coefficient are changed at the same time. The proportion of the exponential function in the frequency is more than that in the torque at a low wind speed. Torque suppression is reduced and inertial power at the present level is released to the greatest extent possible. As the wind speed increases, so does the active power. Because the requirements for torque change on the shaft torque are higher, the proportion of the exponential function in the frequency is less than that in the torque at high wind speed. The change in the exponential function can also increase the proportion of torque weight coefficient to limit the inertial power.

$$
\begin{gathered}
\alpha \%+\beta \%+\gamma \%=1 \\
\alpha \prime+\beta\left(P_{f} / P_{s}\right)^{2}+\gamma\left(P_{f} / P_{s}\right)^{5}=1
\end{gathered}
$$

Since the wind prediction still has a certain error, the strategy of the dynamic weight coefficient needs to be reserved under a certain margin when selecting the standard coefficient under different working conditions. The actual application of the PMSG with different parameters under different conditions also needs to be debugged and processed.

\subsection{Steps for Multi-Objective MPC}

The current-frequency-torque multi-objective MPC has been introduced and analyzed. The specific step flow can be divided into seven steps and the specific algorithm control flow chart is as follows in Figure 6.

Step (1): The stator current, rotor speed, and rotor position angle at the current moment are measured, and the $d-q$ axis current by PARK transformation is calculated for the cost function.

Step (2): According to different switching states, the stator voltages of the $d-q$ axis corresponding to the voltage vectors at instant $k+1$ are calculated for the current prediction calculation.

Step (3): According to the current prediction in Equation (3), the predicted current at instant $k+1$ corresponding to different vectors is calculated, and then the predicted current at instant $k+2$ is calculated.

Step (4): From the predicted current value, the deviation component is extracted, and the predicted frequency at instant $k+2$ is calculated in Equation (22).

Step (5): Based on the predicted current value and the flux equation, the predicted electromagnetic torque at instant $k+2$ is calculated in Equation (34).

Step (6): The cost function under different switching vectors is calculated by rolling optimization, the minimum value is calculated in Equation (30), and the corresponding switching vector is selected.

Step (7): The corresponding optimal switch state is saved and sent to converter. 


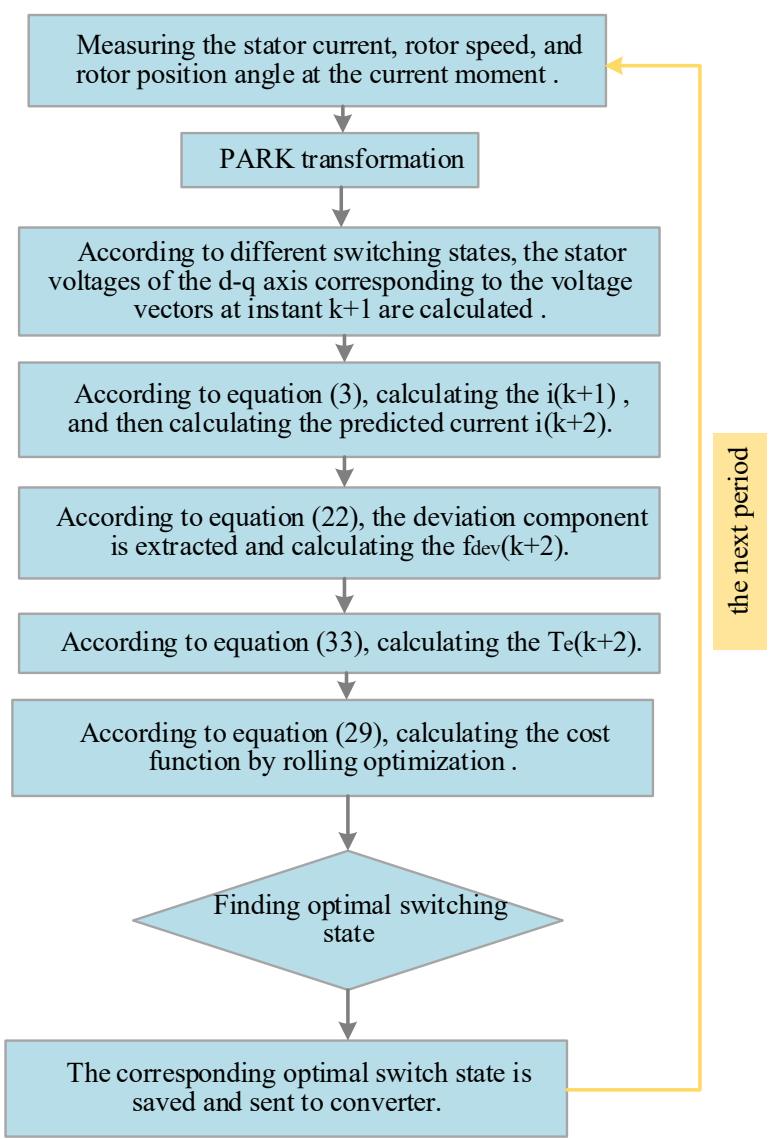

Figure 6. The specific algorithm control flow chart.

The steps listed above are operated in one switch period. After finishing step (7), the next period will run step (1) again.

\section{Simulation}

The simulation system is shown in Figure 4. In the simulation system, the analog synchronous generator (SG) and equivalent load are used as equivalents to reflect the equivalent analog power grid for better reflecting the frequency response characteristics of the actual power grid. This method can more truly reflect the electromagnetic coupling characteristics of the SG set in the actual power grid. The frequency response characteristic simulation system can simulate the inertial response characteristic and frequency modulation characteristic of SG. Meanwhile, the terminal voltage control system can maintain the stability of the voltage at PCC point. At the same time, the corresponding line impedance is added to more truly fit the actual situation of the power grid [41].

The simulation software uses MATLAB/SIMULINK, and the simulation can be conducted according to different control strategies that affect the inertia capability of PMSGbased WT. $S$ is the synchronous generator, and Load 0 and Load 1 are two local loads, where wind power as new energy accounted for $50 \%$ of the total energy of the system. The PMSG-based WT and the synchronous generator each generates 2 MW. In this paper, a sudden increase in the load is adopted to change the system frequency.

\subsection{Simulation for Double-Objective MPC under Disturbance}

To verify the inertial support capability of current-frequency double-objective MPC, it is assumed that the wind speed is constant, and the one-mass structure in the drive train model is adopted. The load increases from 1.00 p.u. to 1.05 p.u. at $10 \mathrm{~s}$, resulting in a significant frequency drop. Figure 7 displays the frequency, active power, electromagnetic torque, and speed of the three different controls. As shown in Figure 7a, when the PMSG- 
based WTs adopts a different control strategy, the maximum frequency deviation decreases from 0.00905 p.u. to 0.0072 p.u. by adopting the double-objective MPC. The frequency deviation of double-objective MPC is less than conventional control with inertia, and the double-objective MPC has a better frequency support capability and decreases the inertial response time. In Figure $7 b-d$, the maximum virtual inertial power rises from 0 p.u. to 0.022 p.u., and the maximum electromagnetic torque fluctuation rises from 0 p.u. to 0.051 p.u.

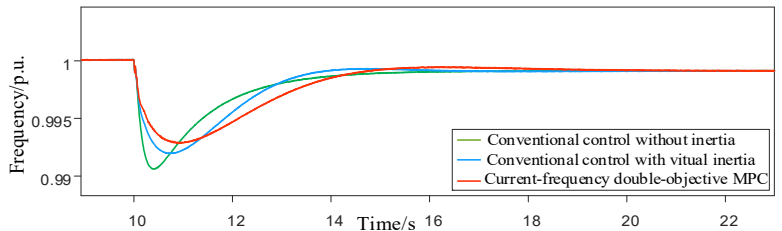

(a)

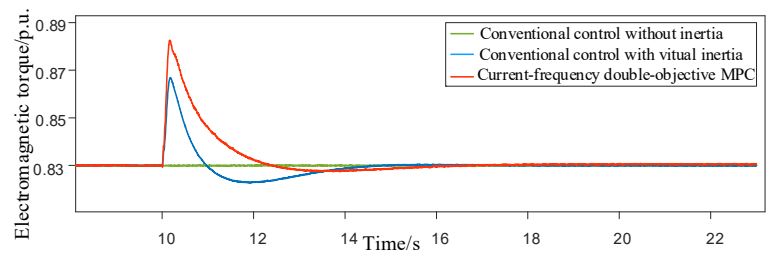

(c)

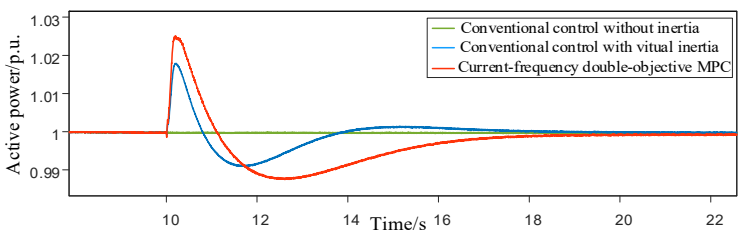

(b)

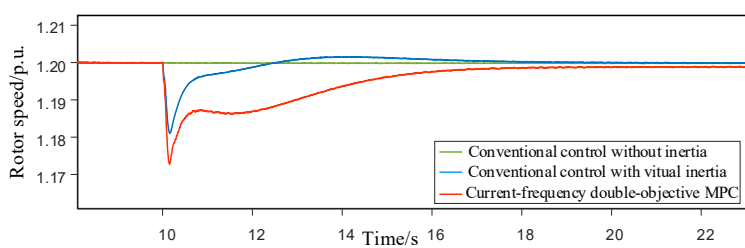

(d)

Figure 7. Comparison of the inertial response of different control strategies. (a-d) are frequency, active power, electromagnetic torque and rotor speed respectively.

Figure 8 displays the effects of successively increasing $\lambda_{f}$ of the cost function to 0.1 , 0.2 , and 0.3. The load increases from 1.00 p.u. to 1.05 p.u. at 10 s. As shown in Figure 8a, with $\lambda_{f}$ increasing, the maximum frequency deviations are 0.0077 p.u., 0.0072 p.u. and 0.0064 p.u., respectively. This proves that the inertia support capability is proportional to $\lambda_{f}$. In Figure $8 \mathrm{~b}-\mathrm{d}$, the fluctuation of active power, electromagnetic torque, and speed becomes apparent with an increase in $\lambda_{f}$. With $\lambda_{f}$ increasing, the maximum inertial powers are 0.019 p.u., 0.024 p.u., and 0.029 p.u. respectively. This proves that more inertial power is added to the system in the frequency response, and the advantages of double-objective MPC are demonstrated.

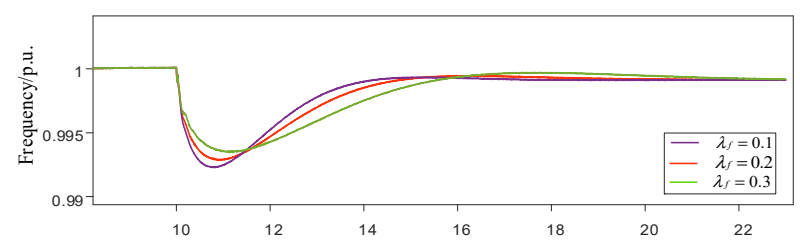

(a)

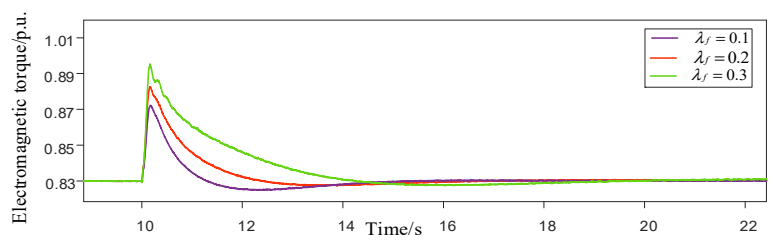

(c)

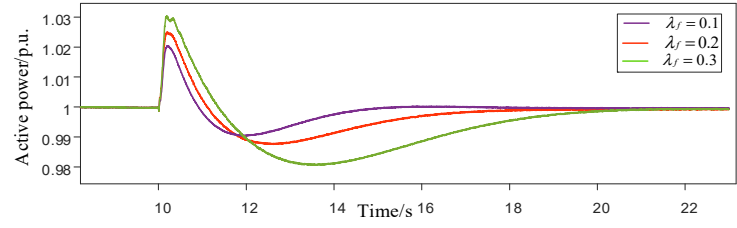

(b)

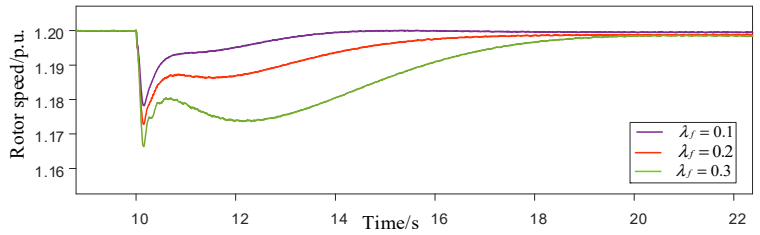

(d)

Figure 8. Comparison of different frequency weight coefficients. (a-d) are frequency, active power, electromagnetic torque and rotor speed respectively. 


\subsection{Simulation for Multi-Objective MPC under the Shafting Oscillation}

The two-mass structure in the drive train model is adopted, and the parameter is set in the case that it excites oscillation during the load disturbance. Figure 9 displays a comparison of the conventional inertia control, current-frequency double-objective MPC and current-frequency-torque multi-objective MPC. The load increases from 1.00 p.u. to 1.05 p.u. at $10 \mathrm{~s}$, resulting in a significant frequency drop. The shaft oscillation is excited to generate obvious electromagnetic torque fluctuation under the sudden disturbance of the load in the conventional inertia control. In the conventional inertia control, the maximum frequency deviation is 0.0090 p.u., and the maximum electromagnetic torque fluctuation is 0.050 p.u. The shaft oscillation affects the control of the frequency, power, and rotor speed. This makes the frequency drop more obvious and the fluctuations of the power and speed more severe. When the current-frequency double-objective MPC is adopted, since the cost function is aimed at the frequency deviation, a larger virtual inertia power is generated. At the same time, the shaft oscillation is amplified, and the system may lose stability beyond the limit range. In the current-frequency double-objective MPC control, the maximum frequency deviation is 0.0092 p.u. and the maximum electromagnetic torque fluctuation is $0.062 \mathrm{p} . \mathrm{u}$. When current-frequency-torque multi-objective MPC is adopted, the electromagnetic torque in the system is limited. When the torque ripple is reduced, the fluctuation of the system frequency, power, and speed is also weakened. The maximum frequency deviation is $0.0082 \mathrm{p} . \mathrm{u}$. and the maximum electromagnetic torque fluctuation is 0.035 p.u.

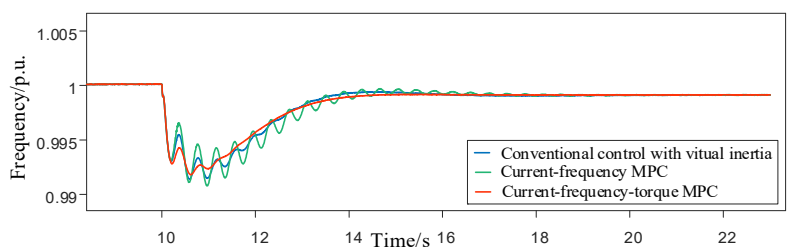

(a)

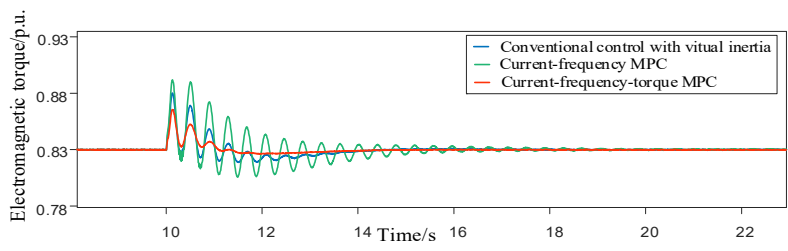

(c)

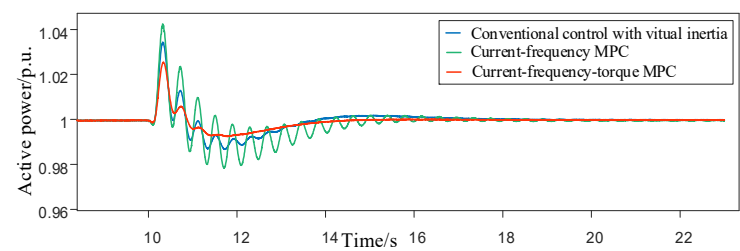

(b)

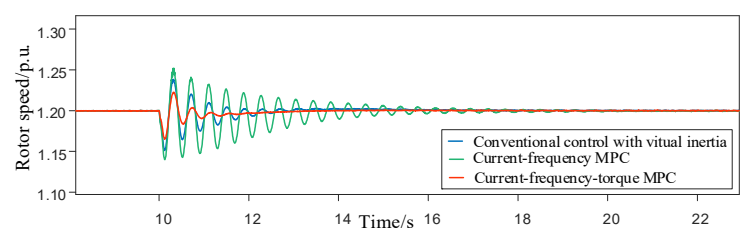

(d)

Figure 9. Comparison of different control strategies under the shafting oscillation. (a-d) are frequency, active power, electromagnetic torque and rotor speed respectively.

Figure 10 displays the comparison of the different $\lambda_{T}$ values of the multi-objective MPC under the shaft oscillation, in which the weight coefficients of the current and frequency remain unchanged and the $\lambda_{T}$ values are $0.1,0.2$, and 0.3 , respectively. It can be inferred from Figure 10c that when the multi-objective MPC is adopted, the electromagnetic torque fluctuation of the system under shaft oscillation gradually decreases with an increase in the torque weight coefficient. The maximum electromagnetic torque fluctuation of the three strategies is 0.062 p.u., 0.041 p.u., and 0.023 p.u., respectively. It can be inferred from Figure $10 \mathrm{a}, \mathrm{b}, \mathrm{d}$ that as the fluctuation of electromagnetic torque decreases gradually, the fluctuations in the frequency, active power, and rotor speed of the PMSG-based wind turbine decrease. The results show that the suppression of the shafting vibration can be enhanced by increasing the weight of the electromagnetic torque. 


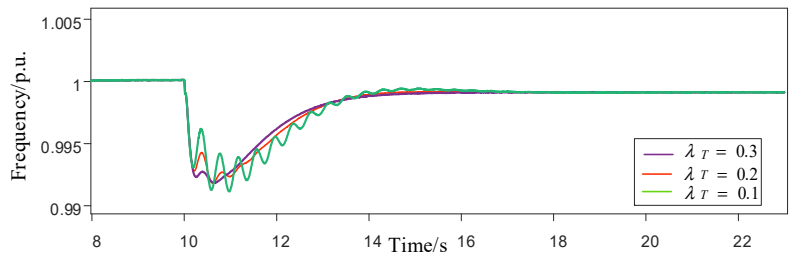

(a)

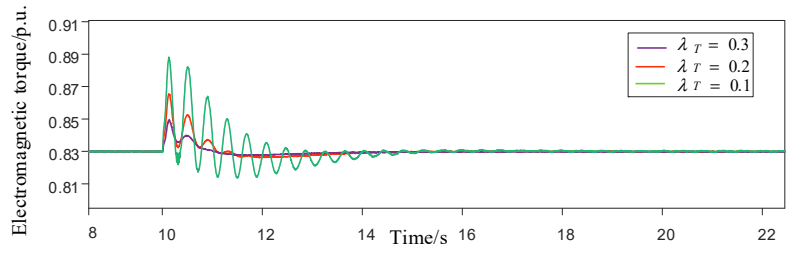

(c)

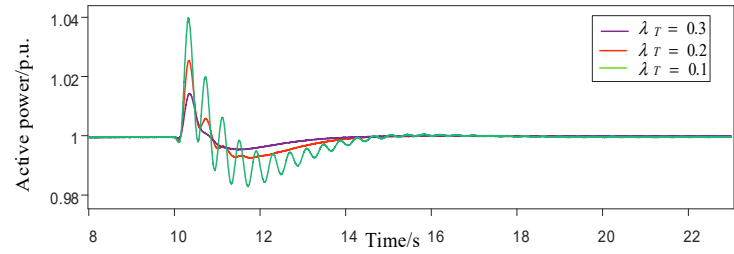

(b)

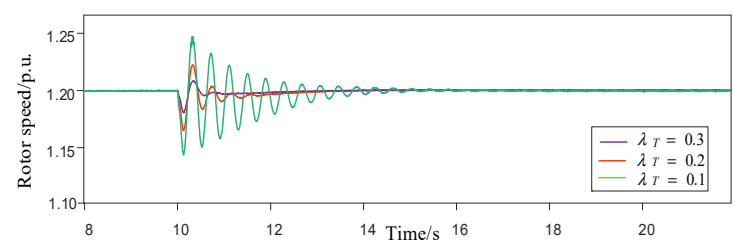

(d)

Figure 10. Comparison of different torque weight coefficients. (a-d) are frequency, active power, electromagnetic torque and rotor speed respectively.

\subsection{Simulation for Dynamic Weight Coefficients under Different Wind Speeds}

In this part, the low wind speed is 0.90 p.u. and the high wind speed is 1.10 p.u. to achieve different working conditions. The load increases from 1.00 p.u. to 1.05 p.u. at $10 \mathrm{~s}$, resulting in a significant frequency drop. The dynamic weight coefficient control with wind speed forecasting, the constant weighting coefficient control, and conventional inertial control are compared. Due to the high proportion of the WT, wind power has a great influence on the output active power. The simulation assumes that the wind turbine works in the MPPT area at a low wind speed. At high wind speeds, due to the limitation of the power, the output power is constant at $1.00 \mathrm{p} . \mathrm{u}$. and the rotor speed is constant at 1.2 p.u.

It can be inferred from Figure 11a,b that when the wind speed is low, the control strategy of the constant weight coefficient and the dynamic weight coefficient can achieve a superior effect compared to the conventional inertia control. The increase in the virtual inertia power leads to a decrease in frequency deviation. As shown in Figure 11c,d, since the output power of the system is low, the limit for the shaft torque variation is not too high. The maximum electromagnetic torques variation of the three strategies are 0.048 p.u., 0.036 p.u., and 0.046 p.u., respectively. The output difference of electromagnetic torque between the constant weight coefficient and the dynamic weight coefficient control strategy is 0.002 p.u., which is not significantly different.

In Figure 12, the difference between different wind speeds is more obvious. The maximum electromagnetic torque fluctuations of the three strategies are 0.035 p.u., 0.055 p.u., and 0.042 p.u., respectively, and the inertial power are 0.020 p.u., 0.029 p.u., and 0.025 p.u., respectively. Under the high wind speed, the dynamic weight coefficient strategy rapidly increases $\lambda_{T}$ at a high wind speed, and the large electromagnetic torque variation is suppressed, but it still has more inertial power than conventional inertia control. Based on the above analysis of the exponential function characteristics, it is shown that the electromagnetic torque fluctuation can be effectively restrained by changing the dynamic weight coefficient. In this way, the electromagnetic torque variation caused by the sudden change in the wind speed is reduced, and the shaft oscillation generated under various disturbances, such as the load change, can be prevented.

The main parameters of the simulation used in this paper are in Appendix A. 


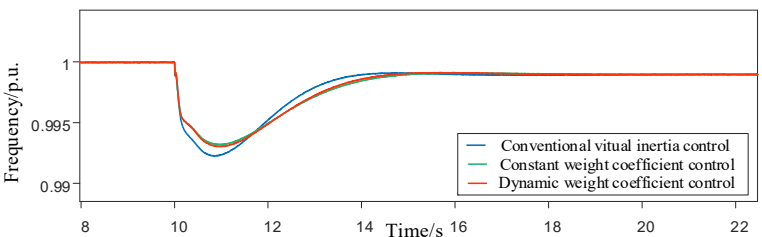

(a)

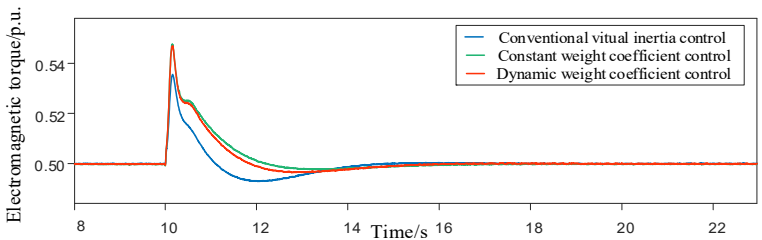

(c)

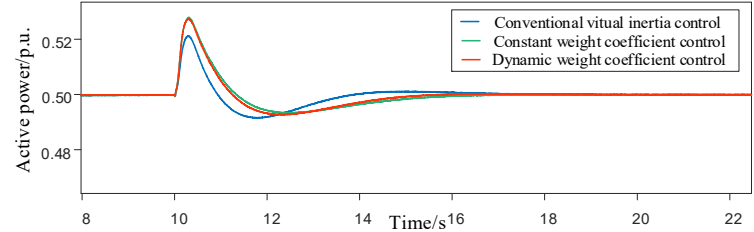

(b)

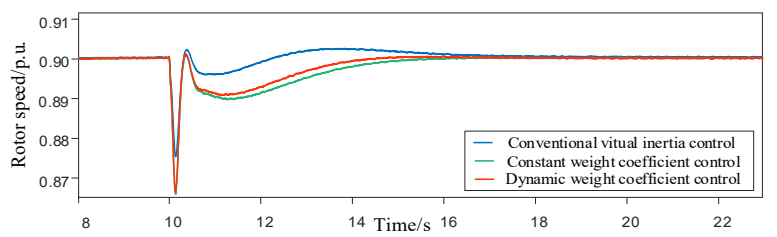

(d)

Figure 11. Comparison of different control strategies under low wind speeds. (a-d) are frequency, active power, electromagnetic torque and rotor speed respectively.

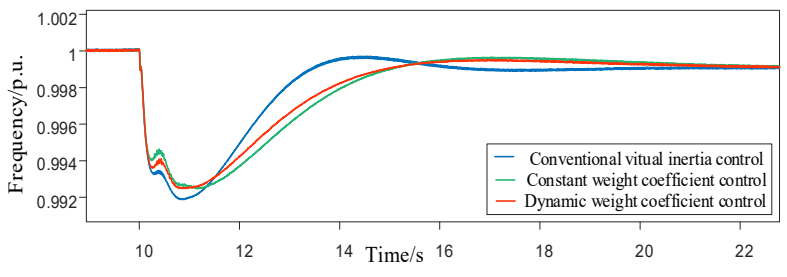

(a)

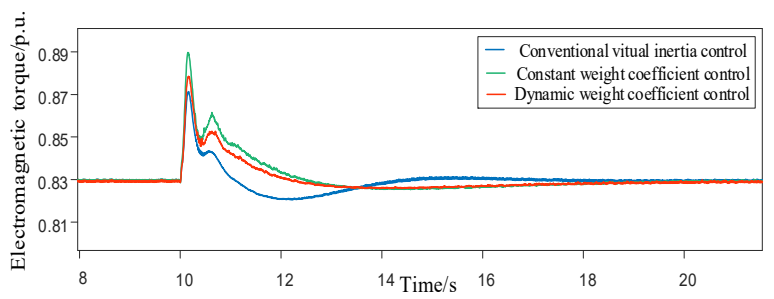

(c)

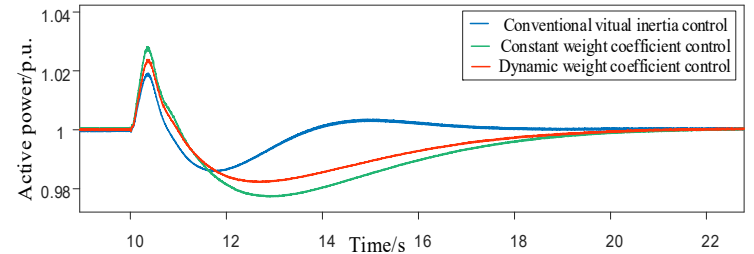

(b)

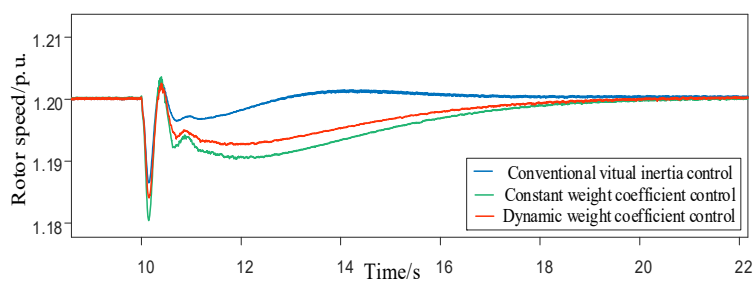

(d)

Figure 12. Comparison of different control strategies under high wind speed. (a-d) are frequency, active power, electromagnetic torque and rotor speed respectively.

\section{Conclusions}

This paper proposed an improved virtual inertia control strategy for PMSG-based WTs based on multi-objective MPC, which is able to compensate the virtual inertia better than the conventional inertia control. It is shown that by changing the weight coefficient according to the inertia demand of the PMSG-based WTs, the inertia response of the system can be enhanced. To suppress the shaft oscillation caused by the high inertia, the electromagnetic torque prediction model is added to the cost function, and the capacity of suppressing the shaft oscillation is flexibly adjusted by changing the weight coefficient. Furthermore, under different wind speeds, the control capability of each objective is changed by the dynamic weight coefficient. The control effect of this paper is simulated in cases with a high wind speed and a low wind speed, where the electromagnetic torque is limited at a high wind speed. To conclude, multi-objective factors were considered in this paper to improve the virtual inertia control of PMSG-based WTs, and the effect of the improvement was verified. 
In addition, stability analysis of the proposed algorithm including the variable-weighting coefficient can be addressed in future works.

Author Contributions: Conceptualization, S.Q.; Formal analysis, Y.C.; Methodology, S.L.; Resources, Z.X. All authors have read and agreed to the published version of the manuscript.

Funding: This work was supported by the National Key Research and Development Program of Chinaunder Grant 2018YFB0904000.

Conflicts of Interest: The authors declare no conflict of interest.

\title{
Nomenclature
}

\author{
$u, i, i_{g}, \quad$ e Stator voltage, Stator current, Grid current, Electromotive force \\ $R_{S}, L \quad$ Stator resistance, Equivalent inductance of stator winding \\ $\psi_{f}, \psi \quad$ Permanent magnet flux linkage, Stator flux linkage \\ $\omega_{r}, \omega_{g}, \omega_{e} \quad$ Rotational speeds of the wind turbine, Rotor angular velocity, Electrical angular velocity \\ $p, p_{n} \quad$ Differential operator, Pole pairs \\ $\Omega, \theta_{g}, \theta_{s} \quad$ Mechanical angular velocity, Grid angle, Torsion angle \\ $K_{S}, B_{S} \quad$ Equivalent stiffness coefficient, Friction coefficient \\ $J_{r}, J_{g} \quad$ Rotary inertia of the wind wheel and the motor \\ $f_{g}, f_{r e f} \quad$ Grid frequency, Grid frequency reference \\ $f_{\text {meas }}, f_{\text {dev }} \quad$ Measured grid frequency, Frequency deviation \\ $K_{d}, K_{p}, K_{f} \quad$ Inertia differential coefficient, Inertia proportional coefficient, Inertia T \\ compensation coefficient \\ $P_{e}, P_{W T}, P_{M P P T} \quad$ Active power, PMSG input power, MPPT power \\ $P_{V I C}, P_{d e v}, P_{e s} \quad$ Virtual inertia power, Active power deviation, Steady-state component power \\ $P_{S}, P_{f} \quad$ Standard active power, Calculated active power by wind speed forecasting \\ $T_{r}, T_{e}, M, D \quad$ Wind torque, Electromagnetic torque, Mechanical inertia, Mechanical damping \\ $i_{\text {ref }}, f_{\text {dev }, n} \quad$ Reference value of the steady-state current, Rated value of the frequency deviation \\ $T_{e, n, J} \quad$ Rated value of the electromagnetic torque, Cost function \\ $\alpha, \beta, \gamma \quad$ Weighting factors \\ $\lambda_{I}, \lambda_{f}, \lambda_{T} \quad$ Current, torque and frequency proportion after standardized \\ $T_{S}, \alpha^{\prime} \quad$ Sampling time, The changed current weight coefficient \\ $U_{d c}, S \quad$ DC-link voltage, Switch vector \\ $d, q \quad \mathrm{dq}$-frame rotating coordinate system \\ $\begin{array}{ll}g & \text { Grid side control variables } \\ * & \text { Reference value }\end{array}$
}

\section{Appendix A}

The main parameters of the simulation used in this paper are as follow (see Tables A1-A3).

Table A1. Simulation system parameters.

\begin{tabular}{ll}
\hline Rated voltage & $690 \mathrm{~V}$ \\
Rated frequency & $50 \mathrm{~Hz}$ \\
Load 0 & $2 \mathrm{MW}$ \\
Load 1 & $0.1 \mathrm{MW}$ \\
\hline
\end{tabular}

Table A2. Parameters of synchronous generator.

\begin{tabular}{ll}
\hline Rated voltage & $690 \mathrm{~V}$ \\
Rated power & $2 \mathrm{MW}$ \\
Rated speed & $1500 \mathrm{rpm}$ \\
Stator phase resistance & $0.00076 \Omega$ \\
$L_{m d}$ & $0.0005246 \mathrm{H}$ \\
$L_{m q}$ & $0.0003845 \mathrm{H}$ \\
$J$ & $49.81 \mathrm{~kg} / \mathrm{m}^{2}$ \\
Pole pairs & 2 \\
\hline
\end{tabular}


Table A3. Parameters of PMSG-based WT.

\begin{tabular}{llll}
\hline Rated voltage & $690 \mathrm{~V}$ & Wind turbine inertia constant & $4.2 \mathrm{~s}$ \\
$T_{\mathrm{s}}$ & $2 \mathrm{kHz}$ & The coefficient of friction & $1.6 \mathrm{~N} \cdot \mathrm{m} \cdot \mathrm{s} / \mathrm{rad}$ \\
Rated power & $2 \mathrm{MW}$ & $L_{d}$ & $0.00142 \mathrm{H}$ \\
Sampling time & $10 \times 10^{-6} \mathrm{~s}$ & $L_{q}$ & $0.00275 \mathrm{H}$ \\
Rated wind speed & $15 \mathrm{~m} / \mathrm{s}$ & Pole pairs & 30 \\
Stator phase resistance & $0.0078 \Omega$ & Rated DC-link voltage & $1100 \mathrm{~V}$ \\
\hline
\end{tabular}

\section{References}

1. Blaabjerg, F.; Teodorescu, R.; Liserre, M.; Timbus, A.V. Overview of Control and Grid Synchronization for Distributed Power Generation Systems. IEEE Trans. Ind. Electron. 2006, 53, 1398-1409. [CrossRef]

2. Chen, Z.; Guerrero, J.M.; Blaabjerg, F. A review of the state of the art of power electronics for wind turbines. IEEE Trans. Power Electron. 2009, 24, 1859-1875. [CrossRef]

3. Wang, S.; Tomsovic, K. Fast Frequency Support from Wind Turbine Generators with Auxiliary Dynamic Demand Control. IEEE Trans. Power Syst. 2019, 34, 3340-3348. [CrossRef]

4. Krpan, M.; Kuzle, I. Inertial and primary frequency response model of variable-speed wind turbines. J. Eng. 2017, 2017, 844-848. [CrossRef]

5. MacDowell, J.; Dutta, S.; Richwine, M.; Achilles, S.; Miller, N. Serving the Future: Advanced Wind Generation Technology Supports Ancillary Services. IEEE Power Energy Mag. 2015, 13, 22-30. [CrossRef]

6. Huang, L.; Xin, H.; Zhang, L.; Wang, Z.; Wu, K.; Wang, H. Synchronization and Frequency Regulation of DFIG-Based Wind Turbine Generators With Synchronized Control. IEEE Trans. Energy Convers. 2017, 32, 1251-1262. [CrossRef]

7. Sang, S.; Zhang, C.; Cai, X.; Molinas, M.; Zhang, J.; Rao, F. Control of a Type-IV Wind Turbine With the Capability of Robust Grid-Synchronization and Inertial Response for Weak Grid Stable Operation. IEEE Access 2019, 7, 58553-58569. [CrossRef]

8. Shao, H.; Cai, X.; Zhou, D.; Li, Z.; Zheng, D.; Cao, Y.; Wang, Y.; Rao, F. Equivalent Modeling and Comprehensive Evaluation of Inertia Emulation Control Strategy for DFIG Wind Turbine Generator. IEEE Access 2019, 7, 64798-64811. [CrossRef]

9. Huang, L.; Xin, H.; Wang, Z.; Wu, K.; Wang, H.; Hu, J.; Lu, C. A Virtual Synchronous Control for Voltage-Source Converters Utilizing Dynamics of DC-Link Capacitor to Realize Self-Synchronization. IEEE J. Emerg. Sel. Top. Power Electron. 2017, 5, 1565-1577. [CrossRef]

10. Wang, S.; Hu, J.; Yuan, X.; Sun, L. On Inertial Dynamics of Virtual-Synchronous-Controlled DFIG-Based Wind Turbines. IEEE Trans. Energy Convers. 2015, 30, 1691-1702. [CrossRef]

11. Nasiri, M.; Mobayen, S.; Faridpak, B.; Fekih, A.; Chang, A. Small-Signal Modeling of PMSG-Based Wind Turbine for Low Voltage Ride-Through and Artificial Intelligent Studies. Energies 2020, 13, 6685. [CrossRef]

12. Wang, Y.; Meng, J.; Zhang, X.; Xu, L. Control of PMSG-Based Wind Turbines for System Inertial Response and Power Oscillation Damping. IEEE Trans. Sustain. Energy 2015, 6, 565-574. [CrossRef]

13. Attya, A.B.; Ademi, S.; Jovanović, M.; Anaya-Lara, O. Frequency support using doubly fed induction and reluctance wind turbine generators. Int. J. Electron. Power Energy Syst. 2018, 101, 403-414. [CrossRef]

14. Peng, B.; Zhang, F.; Liang, J.; Ding, L.; Liang, Z.; Wu, Q. Coordinated control strategy for the short-term frequency response of a DFIG-ES system based on wind speed zone classification and fuzzy logic control. Int. J. Electr. Power Energy Syst. 2019, 107, 363-378. [CrossRef]

15. Ma, J.; Qiu, Y.; Li, Y.; Zhang, W.; Song, Z.; Thorp, J.S. Research on the Impact of DFIG Virtual Inertia Control on Power System Small-Signal Stability Considering the Phase-Locked Loop. IEEE Trans. Power Syst. 2016, 32, 2094-2105. [CrossRef]

16. Arani, M.F.; Mohamed, A.R.I. Analysis and Damping of Mechanical Resonance of Wind Power Generators Contributing to Frequency Regulation. IEEE Trans. Power Syst. 2016, 32, 3195-3204. [CrossRef]

17. Arani, M.F.; Mohamed, A.R.I. Analysis and Mitigation of Undesirable Impacts of Implementing Frequency Support Controllers in Wind Power Generation. IEEE Trans. Energy Convers. 2016, 31, 174-186. [CrossRef]

18. Zhao, H.; Wu, Q.; Guo, Q.; Sun, H.; Xue, Y. Optimal active power control of a wind farm equipped with energy storage system based on distributed model predictive control. IET Gener. Transm. Distrib. 2016, 10, 669-677. [CrossRef]

19. Wang, H.; Yang, J.; Ma, Y.; Xing, Z.; Zhe, C. Model predictive control of PMSG-based wind turbines for frequency regulation in an isolated grid. IEEE Trans. Ind. Appl. 2017, 56, 1536-1541. [CrossRef]

20. Hackl, C.M.; Larcher, F.; Dötlinger, A.; Kennel, R.M. Is multiple-objective model-predictive control “optimal”? In Proceedings of the 2013 IEEE International Symposium on Sensorless Control for Electrical Drives and Predictive Control of Electrical Drives and Power Electronics (SLED/PRECEDE), Munich, Germany, 17-19 October 2013; pp. 1-8.

21. Zhang, Y.; Xu, D.; Liu, J.; Gao, S.; Xu, W. Performance Improvement of Model-Predictive Current Control of Permanent Magnet Synchronous Motor Drives. IEEE Trans. Ind. Appl. 2017, 53, 3683-3695. [CrossRef]

22. Vazquez, S.; Rodriguez, J.; Rivera, M.; Franquelo, L.G.; Norambuena, M. Model Predictive Control for Power Converters and Drives: Advances and Trends. IEEE Trans. Ind. Electron. 2017, 64, 935-947. [CrossRef] 
23. Mishra, R.; Saha, T.K. Performance Analysis of Model Predictive Technique Based Combined Control for PMSG-Based Distributed Generation Unit. IEEE Trans. Ind. Electron. 2020, 67, 8991-9000. [CrossRef]

24. Gao, X.; Abdelrahem, M.; Hackl, C.M.; Zhang, Z.; Kennel, R. Direct Predictive Speed Control With a Sliding Manifold Term for PMSM Drives. IEEE J. Emerg. Sel. Top. Power Electron. 2019, 8, 1258-1267. [CrossRef]

25. Chen, J.; Gong, C. On Optimizing the Aerodynamic Load Acting on the Turbine Shaft of PMSG-Based Direct-Drive Wind Energy Conversion System. IEEE Trans. Ind. Electron. 2014, 61, 4022-4031. [CrossRef]

26. Geng, H.; Xu, D. Stability Analysis and Improvements for Variable-Speed Multipole Permanent Magnet Synchronous GeneratorBased Wind Energy Conversion System. IEEE Trans. Sustain. Energy 2011, 2, 459-467. [CrossRef]

27. Huang, H.; Ju, P.; Jin, Y.; Yuan, X.; Qin, C.; Pan, X.; Zang, X. Generic System Frequency Response Model for Power Grids with Different Generations. IEEE Access 2020, 8, 14314-14321. [CrossRef]

28. Nguyen, N.; Mitra, J. Reliability of Power System with High Wind Penetration under Frequency Stability Constraint. IEEE Trans. Power Syst. 2018, 33, 985-994. [CrossRef]

29. Zhang, Y.; Jin, J.; Huang, L. Model-Free Predictive Current Control of PMSM Drives Based on Extended State Observer Using Ultra-Local Model. IEEE Trans. Ind. Electron. 2020, 68, 993-1003. [CrossRef]

30. Wang, F.; He, L. FPGA-Based Predictive Speed Control for PMSM System Using Integral Sliding-Mode Disturbance Observer. IEEE Trans. Ind. Electron. 2021, 68, 972-981. [CrossRef]

31. Preindl, M.; Bolognani, S. Model Predictive Direct Speed Control with Finite Control Set of PMSM Drive Systems. IEEE Trans. Power Electron. 2013, 28, 1007-1015. [CrossRef]

32. Ravanji, M.H.; Canizares, C.A.; Parniani, M. Modeling and Control of Variable Speed Wind Turbine Generators for Frequency Regulation. IEEE Trans. Sustain. Energy 2019, 11, 916-927. [CrossRef]

33. Kouro, S.; Cortes, P.; Vargas, R.; Ammann, U.; Rodriguez, J. Model Predictive Control—A Simple and Powerful Method to Control Power Converters. IEEE Trans. Ind. Electron. 2008, 56, 1826-1838. [CrossRef]

34. Vargas, R.; Ammann, U.; Hudoffsky, B.; Rodriguez, J.; Wheeler, P. Predictive Torque Control of an Induction Machine Fed by a Matrix Converter With Reactive Input Power Control. IEEE Trans. Power Electron. 2010, 25, 1426-1438. [CrossRef]

35. Zhang, C.-Y.; Chen, C.L.P.; Gan, M.; Chen, L. Predictive Deep Boltzmann Machine for Multiperiod Wind Speed Forecasting. IEEE Trans. Sustain. Energy 2015, 6, 1416-1425. [CrossRef]

36. Khodayar, M.; Kaynak, O.; Khodayar, M.E. Rough Deep Neural Architecture for Short-Term Wind Speed Forecasting. IEEE Trans. Ind. Inform. 2017, 13, 2770-2779. [CrossRef]

37. He, Y.; Qin, Y.; Lei, X.; Feng, N. A study on short-term power load probability density forecasting considering wind power effects. Int. J. Electr. Power Energy Syst. 2019, 113, 502-514. [CrossRef]

38. Xie, W.; Wang, X.; Wang, F.; Xu, W.; Kennel, R.; Gerling, D. Dynamic Loss Minimization of Finite Control Set-Model Predictive Torque Control for Electric Drive System. IEEE Trans. Power Electron. 2016, 31, 849-860. [CrossRef]

39. Zhao, J.; Lyu, X.; Fu, Y.; Hu, X.; Li, F. Coordinated Microgrid Frequency Regulation Based on DFIG Variable Coefficient Using Virtual Inertia and Primary Frequency Control. IEEE Trans. Energy Convers. 2016, 31, 833-845. [CrossRef]

40. Hossam, H.M.; Abdel-Raheem, Y.; Essam, E.M. Variable step size P\&O MPPT algorithm for optimal power extraction of multi-phase PMSG based wind generation system. Int. J. Electron. Power Energy Syst. 2019, 108, 218-231.

41. Khatib, A.R.; Appannagari, M.; Manson, S.; Goodall, S. Load Modeling Assumptions: What is Accurate Enough? IEEE Trans. Ind. Appl. 2016, 52, 3611-3619. [CrossRef] 